\title{
Endoscopic endonasal translacerum approach to the inferior petrous apex
}

\author{
Masaaki Taniguchi, MD, PhD, Nobuyuki Akutsu, MD, PhD, Katsu Mizukawa, MD, PhD, \\ Masaaki Kohta, MD, PhD, Hidehito Kimura, MD, PhD, and Eiji Kohmura, MD, PhD \\ Department of Neurosurgery, Kobe University Graduate School of Medicine, Kobe, Hyogo, Japan
}

\begin{abstract}
OBJECTIVE The surgical approach to lesions involving the inferior petrous apex (IPA) is still challenging. The purpose of this study is to demonstrate the anatomical features of the IPA and to assess the applicability of an endoscopic endonasal approach through the foramen lacerum (translacerum approach) to the IPA.

METHODS The surgical simulation of the endoscopic endonasal translacerum approach was conducted in 3 cadaver heads. The same technique was applied in 4 patients harboring tumors involving the IPA ( 3 chordomas and 1 chondrosarcoma).
\end{abstract}

RESULTS By removing the fibrocartilaginous component of the foramen lacerum, a triangular space was created between the anterior genu of the petrous portion of the carotid artery and the eustachian tube, through which the IPA could be approached. The range of the surgical maneuver reached laterally up to the internal auditory canal, jugular foramen, and posterior vertical segment of the petrous portion of the carotid artery. In clinical application, the translacerum approach provided sufficient space to handle tumors at the IPA. Gross-total and partial removal was achieved in 3 and 1 cases, respectively, without permanent surgery-related morbidity and mortality.

CONCLUSIONS The endoscopic endonasal translacerum approach provides reliable access to the IPA. It is indicated alone for lesions confined to the IPA and in combination with other approaches for more extensive lesions.

http://thejns.org/doi/abs/10.3171/2015.1.JNS142526

KEY WORDS endoscopic endonasal approach; eustachian tube; foramen lacerum; inferior petrous apex; petrous portion of the carotid artery; skull base tumor; surgical technique

$\mathrm{T}$

HE lesions involving the inferior petrous apex (IPA), defined as the petrous apex below the horizontal segment of the petrous carotid artery and medial to the internal auditory canal and the jugular foramen, are still among the most challenging to approach. Lateral approaches to those lesions include various degrees of petrosectomy with severing of the eustachian tube (ET) and exposure/translocation of the petrous portion of the carotid artery. ${ }^{7,8,10,15,17,21,22,24,25}$ Despite such invasive procedures, tumor removal around the anterior genu of the carotid artery is restricted. The recent evolution of the endoscopic endonasal approach widened the surgical target to the diverse skull base regions, ${ }^{1,9,11}$ including the jugular tubercle and occipital condyle, by the so-called far-medial approach. ${ }^{6,18}$ However, a reliable access route to the IPA in relation to the surrounding structures, such as the ET and the foramen lacerum (FL), is not yet established.

We conducted an anatomical study simulating the ac- tual endoscopic endonasal surgery and searched for the access corridor to the IPA. In particular, the aim was to preserve the surrounding structures, if possible, during the dissection. The same technique was applied in 4 clinical cases harboring tumors involving the IPA, and its clinical feasibility was evaluated.

\section{Methods}

As the designations for each segment of the internal carotid artery differ within the literature, leading to misunderstanding, the present paper conforms to those described by Osawa et al. ${ }^{19}$ Three formalin-fixed cadavers were used for the anatomical study. The dissection was carried out on 4 sides endoscopically, simulating the actual endoscopic endonasal surgery via both nostrils. After resecting the posterior half of the middle turbinate on the side of the target, the sphenoid sinus was widely opened 
up to the sphenopalatine foramen bilaterally. The medial maxillary wall was opened and the posterior wall of the maxillary sinus was resected to expose the pterygopalatine fossa on the target side. The bone around the vidian canal at the base of the pterygoid process was removed to skeletonize the nerve up to the FL. The bone covering the paraclival carotid artery was removed down to the FL. The medial half of the root of the pterygoid process was further removed to expose the superior surface of the cartilaginous segment of the ET. The fibrocartilage covering the FL was cut close to the superior aspect of the ET, and the cartilage and fibrous ligament within the FL was carefully removed to expose the anterior genu and horizontal segment of the petrous carotid artery. The subsequent removal of the IPA was accomplished through the thuscreated space between the inferior aspect of the horizontal segment of the petrous carotid artery and superior aspect of the ET (translacerum approach).

This surgical technique was applied in 4 patients harboring tumors involving the IPA (Figs. 1 and 2). Unlike the procedure described in the cadaveric study, the Doppler probe was used to determine the exact location of the anterior genu of the petrous carotid artery before incising the fibrocartilage covering the FL, and the exposed carotid artery had to be covered with the nasoseptal flap after the tumor removal had been completed. The demographic data of the patients are listed in Table 1. Inclusion of the patients in this study was approved by the institutional review board of the Kobe University Graduate School of Medicine.

\section{Results \\ Cadaver Dissection}

After wide sphenoidotomy and removal of the medial root of the pterygoid process, the paraclival carotid artery and the cartilaginous segment of the ET were exposed (Fig. $3 \mathrm{~A}$ and $\mathrm{B})$. The sheath of the paraclival carotid artery was contiguous with the fibrocartilage covering the FL (Fig. $3 \mathrm{C}$ and $\mathrm{D})$. To avoid injury to the artery, the incision over the FL had to be started medially and inferiorly just above the superior surface of the ET. Once the FL was opened, the anterior genu became visible, and the residual fibrocartilaginous tissue within the FL could be removed, thereby detaching the anterior genu and horizontal segment of the petrous carotid artery from the surrounding bone and the ET. This maneuver created a triangular space bordered by the inferior aspect of the horizontal segment of the petrous carotid artery, the superior aspect of the ET, and the inferiorly extended line along the medial aspect of the paraclival carotid artery. This space was termed the supra-eustachian triangle, of which a side was approximately $5 \mathrm{~mm}$ (Fig. $3 \mathrm{E}$ and $\mathrm{F}$ ). Using this space, the drilling and curettage of the lower petrous bone with straight and slightly curved instruments became feasible (Fig. $3 \mathrm{G}$ and $\mathrm{H}$ ). With further removal of the lower petrous bone, the jugular foramen and the internal auditory canal with relevant cranial nerves could be exposed in front (Fig. 3I and J). The range of surgical maneuverability reached laterally up to medial aspect of the internal auditory canal, the jugular foramen, and the posterior vertical segment of the petrous carotid
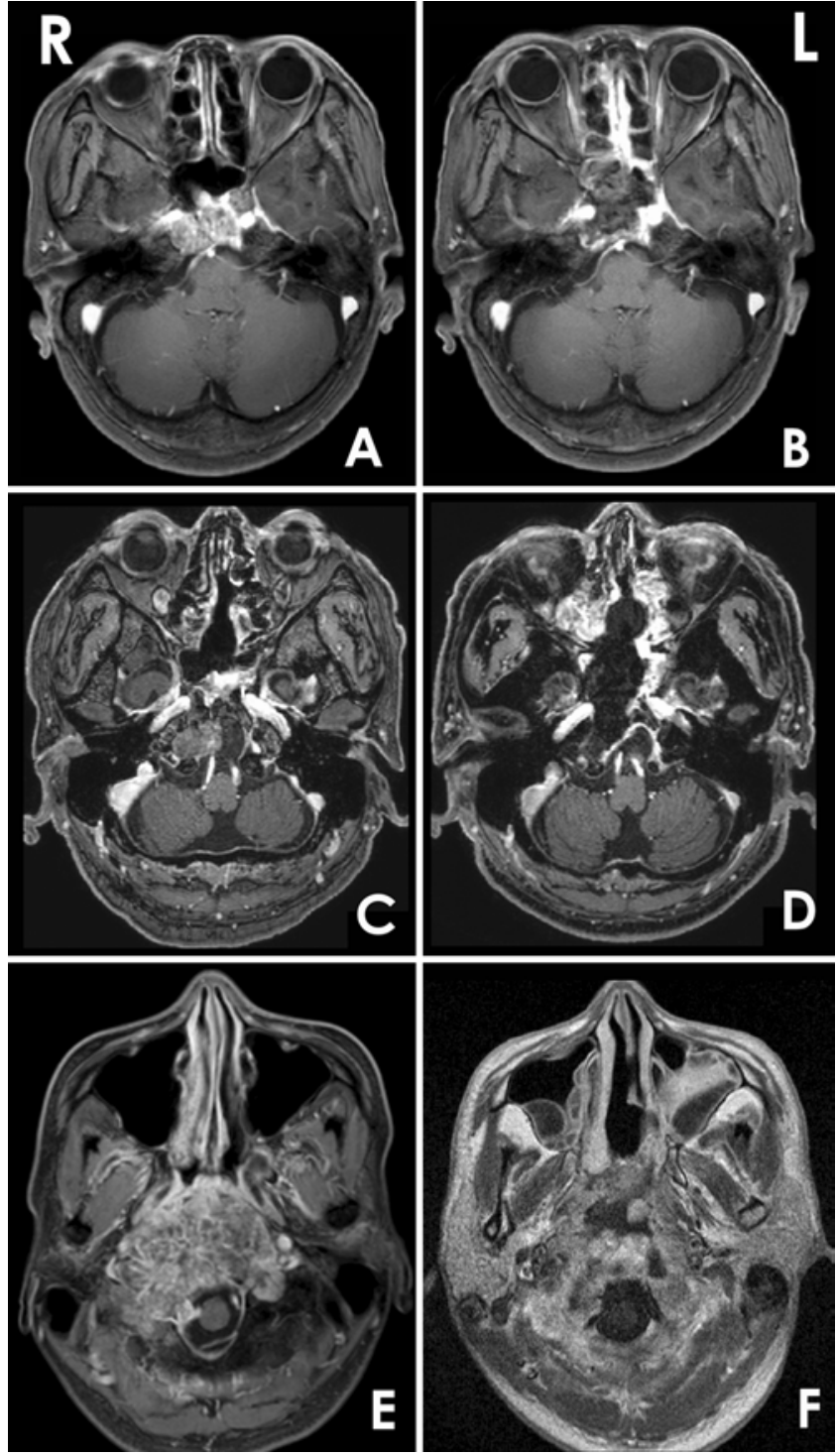

FIG. 1. Patients 1-3. Preoperative (left column) and postoperative (right column) Gd-enhanced, T1-weighted MR images. In Patient 1, the tumor was located in the clivus, extending to the right IPA (A), which was removed gross totally (B). In Patient 2, the tumor was located in the right IPA involving the jugular tubercle (C), which was removed gross totally (D). In Patient 3, the tumor occupied the whole clivus and bilateral occipital condyles (E). The postoperative MR image demonstrates partial tumor removal, especially from the IPA (F). The image quality is mediocre because of the scanning while the head was fixed in the halo vest before performing the second-stage surgery.

artery. The ET and the vidian nerve could be preserved through the whole procedure (Fig. 3K and L). An anatomical simulation of the endoscopic endonasal translacerum approach on the left side can be seen online in Video 1.

VIDEO 1. Anatomical simulation of the endoscopic endonasal translacerum approach on the left side. Copyright Masaaki Taniguchi. Published with permission. Click here to view with Media Player. Click here to view with Quicktime.

\section{Clinical Application}

The size and configuration of the supra-eustachian tri- 

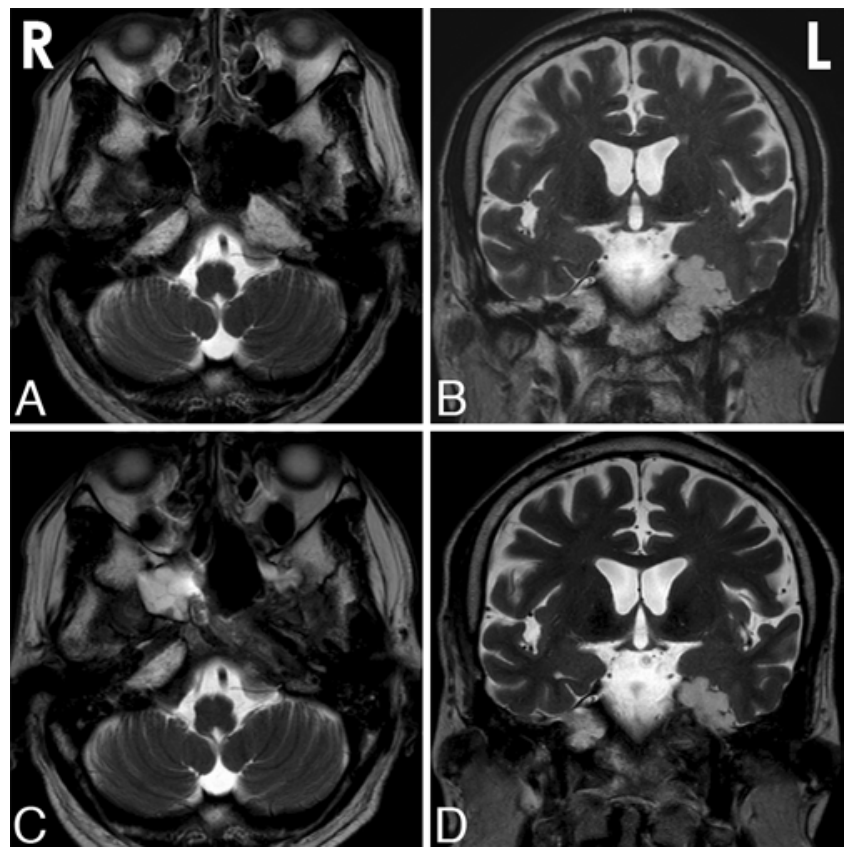

FIG. 2. Patient 4. Preoperative and postoperative axial (left column) and coronal (right column) T2-weighted MR images. The preoperative MR images demonstrate a high-intensity tumor occupying the entire left petrous apex and extending into the middle cranial fossa (A and B). The postoperative MR images demonstrate gross-total removal of the tumor compartment at the IPA (C and D). The residual tumor in the middle cranial fossa was removed subsequently through the subtemporal approach in the planned second-stage surgery.

angle could be roughly estimated from the preoperative coronal T2-weighted MR image (Fig. 4). After exposure of the supra-eustachian triangle, the FL was still covered by the fibrocartilage, which was contiguous with the carotid sheath and the pharyngobasilar fascia (Fig. 5A and B). Thus, the location of the anterior genu was visually not recognizable and had to be determined with the Doppler probe (Fig. 5C and D). By cutting the fibrocartilage just above the ET (Fig. 5E and F), the anterior genu could be exposed and the content within the FL removed without injuring the carotid artery. Profuse bleeding from the inferior petrosal sinus was occasionally encountered but could be managed by plugging with hemostatic absorbable sheets and head elevation. However, care should be taken because of the potential for large blood loss, especially if the surgical operation becomes long. The space provided by opening the supra-eustachian triangle served as the reliable access corridor to the IPA, through which the tumor removal could be accomplished (Fig. $5 \mathrm{G}$ and $\mathrm{H}$ ). Though a $30^{\circ}$-angled endoscope was mostly used to visualize the area, surgical maneuvers could be accomplished with the straight or slightly curved instruments reaching up to the posterior vertical segment of the petrous carotid artery (Fig. 5I and J). The endoscopic endonasal translacerum approach in Patient 4 can be seen online in Video 2.

VIDEO 2. Intraoperative video of the endoscopic endonasal translacerum approach in Patient 4. Copyright Masaaki Taniguchi.

Published with permission. Click here to view with Media Player.

Click here to view with Quicktime.

Gross-total removal was achieved in 3 patients and partial removal in 1 with a huge chordoma occupying the whole clivus involving bilateral occipital condyles (Patient 3) (Figs. 1 and 2). In Patients 1 and 2, the tumor was rather confined and could be removed with only the translacerum approach. In Patient 3, planned staged surgery combined with the transcondylar fossa approach and simultaneous posterior craniovertebral fixation was used. In Patient 4, the subtemporal approach was used. Two patients received heavy-particle irradiation therapy, 1 for high Mib-1 index (36.3\%, Patient 1) and another for the apparent residual tumor (Patient 3). None of the patients had temporary and permanent surgery-related morbidity and mortality, except in Patient 2, who experienced fever of unknown origin without evidence of meningitis, requiring prolonged hospital stay. The ET was functionally preserved in all cases. The follow-up period ranged from 9 to 34 months (median 24 months) without any recurrence and regrowth, except in Patient 1, who demonstrated tiny regrowth of the tumor before the initiation of the adjunctive radiation therapy.

\section{Illustrative Case Patient 4}

A 65-year-old man had been followed up for about 4 years for an asymptomatic tumor in the left petrous apex extending to the middle cranial fossa that demonstrated gradual growth, becoming an indication for surgical removal (Fig. 2A and B). The patient had suffered sudden deafness on the contralateral side to the lesion 3 years prior; therefore, considerations were made to maintain the function of the ET and to prevent conductive hearing disturbance on the affected side. Thus, the tumor at the IPA below the horizontal segment of the petrous carotid artery was removed by the endoscopic endonasal translacerum approach (Fig. 2C and D), and the residual tumor in the middle cranial fossa was removed 1 month later by the subtemporal approach, resulting in gross-total removal. The postoperative course was uneventful, and the hearing function on the left side was maintained in the preoperative level.

\section{Discussion}

Recent advancement in endoscopic endonasal skull base surgery has widened the target of the technique to the various skull base regions., ${ }^{1,911}$ Kassam et al. adequately addressed the IPA in their pioneering work and included it in Zone 2, according to their modular concept. ${ }^{11,12,29}$ Detailed description of the anatomical features and surgical technique in relation to the surrounding structures such as ET and FL is, however, scarce, which renders the IPA still one of the most challenging areas to approach. Though the importance of the ET as an anatomical landmark in approaching the lateral skull base is widely recognized, ${ }^{3-5,20,26}$ management of this structure in approaching the IPA is often mentioned as a subject of resection..$^{14,16,30}$ We advocate the significance of using the triangular space bordered by the inferior aspect of the horizontal segment of the petrous carotid artery, the superior aspect of the ET, and the inferiorly extended line along the medial aspect of the paraclival carotid artery in approaching the IPA, and we termed this triangular space the supra-eustachian 
TABLE 1. Demographic data of the patients operated on using the endoscopic endonasal translacerum approach

\begin{tabular}{|c|c|c|c|c|c|c|c|c|c|}
\hline $\begin{array}{l}\text { Patient } \\
\text { No. }\end{array}$ & $\begin{array}{l}\text { Age (yrs), } \\
\text { Sex }\end{array}$ & Pathology & Length of Op & $\begin{array}{l}\text { Blood Loss } \\
(\mathrm{ml})\end{array}$ & $\begin{array}{l}\text { Staged } \\
\text { Surgery }\end{array}$ & $\begin{array}{c}\text { Tumor } \\
\text { Removal }\end{array}$ & $\begin{array}{l}\text { Hospital Stay } \\
\text { (days) }\end{array}$ & Complication & $\begin{array}{l}\text { Follow-Up (mos) } \\
\text { Adjunct Therapy }\end{array}$ \\
\hline 1 & $63, F$ & Chordoma & $8 \mathrm{hrs} 57 \mathrm{mins}$ & 2360 & None & GTR & 16 & None & 34.5/heavy P \\
\hline 2 & $67, M$ & Chordoma & 5 hrs 3 mins & 280 & None & GTR & 42 & None & 34/none \\
\hline 3 & $29, \mathrm{M}$ & Chordoma & 12 hrs 3 mins & 2400 & Yes* $^{*}$ & Partial & 56 & None & 14/heavy P \\
\hline 4 & $64, M$ & Chondrosarcoma & $10 \mathrm{hrs} 13 \mathrm{mins}$ & 370 & Yest & GTR & 16 & None & 9/none \\
\hline
\end{tabular}

GTR = gross-total removal; heavy $\mathrm{P}=$ heavy-particle irradiation.

* Transcondylar fossa approach plus posterior craniovertebral fixation.

$\dagger$ Subtemporal approach.

triangle. As the FL was included within it, the approach through this triangle was termed the translacerum approach. The supra-eustachian triangle served as a reliable access corridor to the IPA, enabling complete tumor removal within the area, as demonstrated in clinical cases. The most lateral limit of surgical maneuverability through the translacerum approach was just medial to the internal auditory canal, the jugular foramen, and the posterior vertical segment of the petrous carotid artery.

\section{Opening of the FL}

To get access through the supra-eustachian triangle to the IPA, removal of the fibrocartilaginous component within the FL and surrounding bone is necessary. The
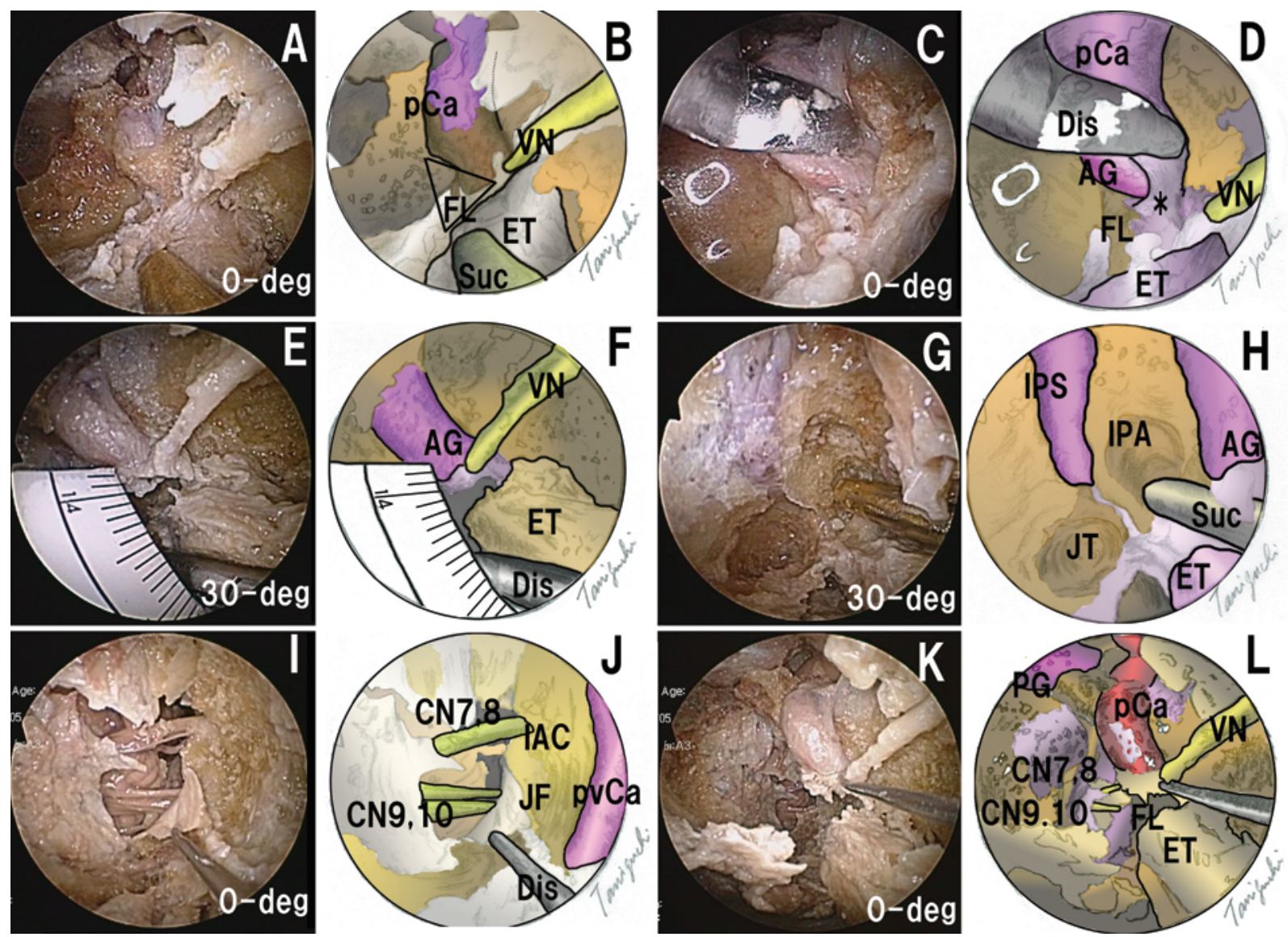

FIG. 3. Photographs (left) and corresponding schemas (right) of the cadaveric dissection demonstrating the translacerum approach to the IPA on the left side. The viewing angle of the endoscope is indicated in the lower right corner of each image. After exposure of the paraclival carotid artery ( $\mathrm{pCa}$ ), the $\mathrm{FL}$, and the $\mathrm{ET}$, the supra-eustachian triangle is defined (outlined in black) (A and B). The magnified view of the anterior genu (AG) of the paraclival carotid artery demonstrates the carotid sheath transitioning to the fibrocartilage of the FL, indicated by the asterisk (asterisk) (C and D). After opening of the FL, a space is created, of which a side is approximately $5 \mathrm{~mm}$ ( $E$ and $F$ ). Through the space, instruments can be inserted to add surgical maneuverability at the IPA $(G$ and $\mathrm{H})$. After anterior inferior petrosectomy, the internal auditory canal (IAC) and jugular foramen (JF) are exposed with the relevant cranial nerves (I and J). The overview of the anatomy demonstrates the straight trajectory to the IPA through the supra-eustachian triangle (K and L). CN 7, 8 = cranial nerve VII and VIII; CN 9, $10=$ cranial nerve IX and X; deg = degree; Dis = dissector; IPS = inferior petrosal sinus; JT = jugular tubercle; $P G=$ pituitary gland; $p v C a=$ posterior vertical segment of carotid artery; Suc = suction tube; VN = vidian nerve. Copyright Masaaki Taniguchi. Published with permission. Figure is available in color online only. 


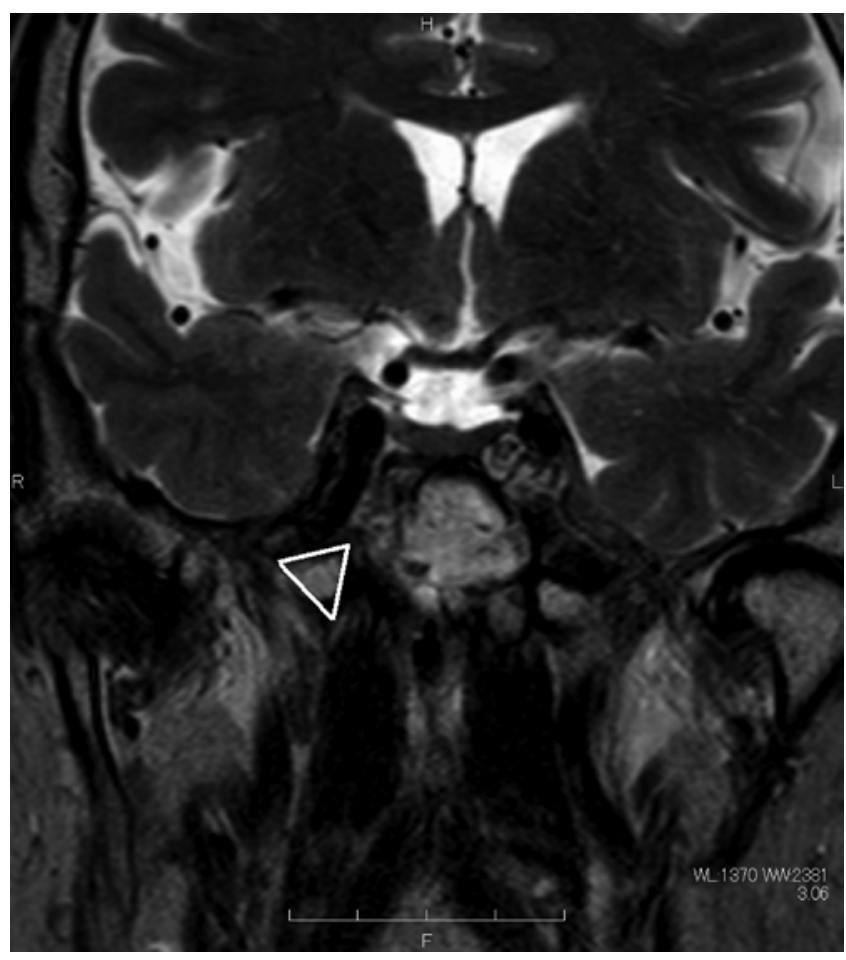

FIG. 4. Patient 1. Preoperative coronal T2-weighted MR image. The size and configuration of the supra-eustachian triangle can be roughly estimated as outlined (triangle).

preoperative evaluation of the coronal T2-weighted MR image is helpful, therefore, to estimate the size and configuration of the triangle. As the fibrocartilage covering the FL is contiguous with the carotid sheath of the paraclival artery and the pharyngobasilar fascia, $, 3,6,7,13,27$ visual inspection alone is not sufficient to determine the location of the anterior genu. Therefore, precise localization of the anterior genu with a micro-Doppler probe becomes mandatory in the clinical setting. The incision of the fibrocartilage covering the FL should also start close to the superior aspect of the ET and distant from the anterior genu. Once the FL is opened, the course of the carotid artery can be traced visually, and the fibrocartilaginous content within the FL can be further removed without injuring the artery.

\section{Preservation of the ET}

The transcranial approach to the IPA requires severing the bony segment of the ET, which results in postoperative otitis media and conductive hearing disturbance. Those sequelae are sometimes not ignorable for patient's quality of life. There are surely cases also involving the endoscopic endonasal approach, in which the sacrifice of the ET becomes mandatory by placing the priority on the cure of the disease or because of the vascularized nature of the lesion. ${ }^{16,30}$ The excessive resection of nasal/paranasal structures, however, may cause additional morbidity. With the accumulation of the experience, precise choice of the entry route for the particular disease in each individual is now becoming feasible. Simal-Julián et al. nicely demonstrated their technique to transposition the ET to approach the jugular tubercle and occipital condyle, and

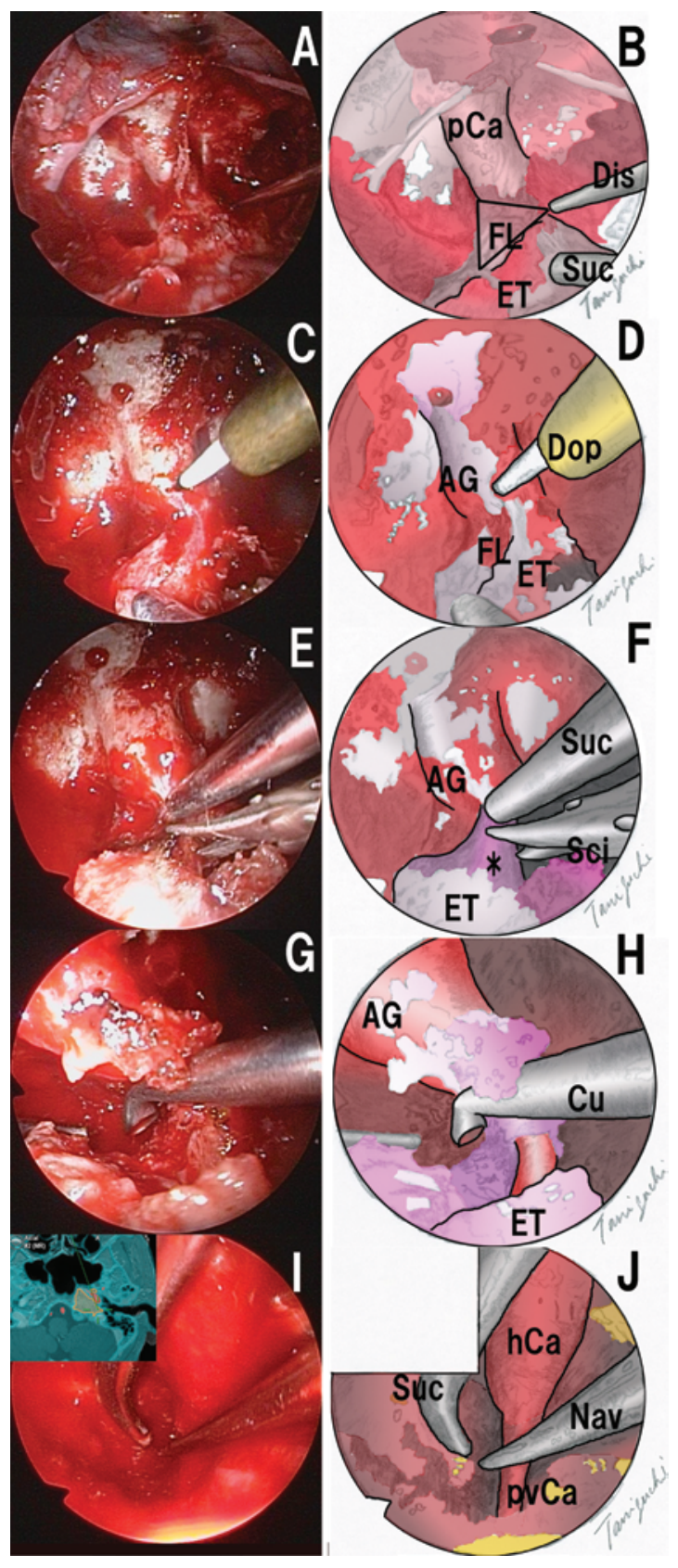

FIG. 5. Patient 4. Intraoperative photographs (left column) and corresponding schemas (right column) of the endoscopic endonasal translacerum approach. All images were taken with the endoscope at a $30^{\circ}$ angle. After wide sphenoidotomy is performed, the paraclival carotid artery, the FL, and the ET are exposed on the left side. The supraeustachian triangle can be recognized as outlined (black lines) (A and $B)$. The location of the AG covered by the carotid sheath is accurately determined with the Doppler probe (Dop) (C and D). The contiguous membrane of the carotid sheath and the fibrocartilage of the FL, indicated by the asterisk, is sharply cut just superior to the ET (E and F). The tumor at the IPA is curetted together with the invaded bone through the space created by opening the FL ( $G$ and $\mathbf{H})$. The straight navigator probe (Nav) reaches the most lateral part of the surgical field just dorsal to the posterior vertical portion of the carotid artery (pvCa), which is confirmed on the navigator screen (inset in I) (I and J). $\mathrm{Cu}=$ curette; $\mathrm{hCa}=$ horizontal segment of the petrous carotid artery; Sci = scissors. See Fig 3 for definitions of other abbreviations. Copyright Masaaki Taniguchi. Published with permission. Figure is available in color online only. 
advocated the importance of preserving the function of the ET. ${ }^{23}$ We agree fully with their argument and consider that the translacerum approach presented in this paper is applicable for more laterally located lesion such as at the IPA, while preserving the ET.

\section{Combination of Less Invasive Approaches}

Every surgical approach has its limitation, especially if weight is given to its being less invasive. As the surgical field provided by the endoscopic endonasal translacerum approach is rather limited, complete tumor removal through such a single approach should be considered for relatively confined lesions; for larger tumors, a combination of different angled approaches should be considered. Accurate knowledge about the range of maneuverability in each of the combined approaches, therefore, becomes important. ${ }^{2}$ Van Gompel et al. quantitatively demonstrated the difference in extent of bone removal between transcranial and endonasal endoscopic anterior petrosectomy. ${ }^{28}$ With the translacerum approach, the bone removal can be extended further laterally, enabling surgical maneuvering at the IPA up to just medial to the internal auditory canal, the jugular foramen, and the posterior vertical segment of the petrous carotid artery. Thus, combining both the endoscopic endonasal and lateral approaches, almost the entire petrous bone can be addressed. However, as the number of the cases is limited and the postoperative follow-up period is still short, further validation of the approach would be required with the accumulation of the cases and longer follow-up.

\section{Conclusions}

The anatomical feature and clinical applicability of the translacerum approach were investigated. Resection of the fibrocartilage within the FL provided a reliable access corridor to the IPA. The range of the surgical maneuver reached laterally up to the medial aspect of the internal auditory canal, the jugular foramen, and the posterior vertical segment of the petrous carotid artery. The tumors occupying the IPA could be removed adequately using the translacerum approach alone or in combination with the transcranial approach, without any complication and while preserving the ET function. The translacerum approach is considered a reliable and less invasive alternative for lesions within the IPA.

\section{Acknowledgments}

We thank the Nojigiku-kai, a volunteer group at the Kobe University Graduate School of Medicine, for body donation, and the Division of Developmental Neurobiology of the Department of Physiology and Cell Biology, Kobe University Graduate School of Medicine, for organizing the anatomical dissection facility.

\section{References}

1. Battaglia P, Turri-Zanoni M, Dallan I, Gallo S, Sica E, Padoan G, et al: Endoscopic endonasal transpterygoid transmaxillary approach to the infratemporal and upper parapharyngeal tumors. Otolaryngol Head Neck Surg 150:696-702, 2014

2. Benet A, Prevedello DM, Carrau RL, Rincon-Torroella J, Fernandez-Miranda JC, Prats-Galino A, et al: Comparative analysis of the transcranial "far lateral" and endoscopic endonasal "far medial" approaches: surgical anatomy and clinical illustration. World Neurosurg 81:385-396, 2014

3. Dallan I, Bignami M, Battaglia P, Castelnuovo P, Tschabitscher M: Fully endoscopic transnasal approach to the jugular foramen: anatomic study and clinical considerations. Neurosurgery 67 (3 Suppl Operative):ons1-ons8, 2010

4. Dallan I, Lenzi R, Bignami M, Battaglia P, Sellari-Franceschini S, Muscatello L, et al: Endoscopic transnasal anatomy of the infratemporal fossa and upper parapharyngeal regions: correlations with traditional perspectives and surgical implications. Minim Invasive Neurosurg 53:261-269, 2010

5. Falcon RT, Rivera-Serrano CM, Miranda JF, Prevedello DM, Snyderman CH, Kassam AB, et al: Endoscopic endonasal dissection of the infratemporal fossa: Anatomic relationships and importance of eustachian tube in the endoscopic skull base surgery. Laryngoscope 121:31-41, 2011

6. Fernandez-Miranda JC, Morera VA, Snyderman CH, Gardner P: Endoscopic endonasal transclival approach to the jugular tubercle. Neurosurgery 71 (1 Suppl Operative):146-159, 2012

7. Funaki T, Matsushima T, Peris-Celda M, Valentine RJ, Joo W, Rhoton AL Jr: Focal transnasal approach to the upper, middle, and lower clivus. Neurosurgery 73 (2 Suppl Operative): $155-191,2013$

8. Goel A: Extended middle fossa approach for petroclival lesions. Acta Neurochir (Wien) 135:78-83, 1995

9. Hofstetter CP, Singh A, Anand VK, Kacker A, Schwartz TH: The endoscopic, endonasal, transmaxillary transpterygoid approach to the pterygopalatine fossa, infratemporal fossa, petrous apex, and the Meckel cave. J Neurosurg 113:967-974, 2010

10. Hitselberger WE, Horn KL, Hankinson H, Brackmann DE, House WF: The middle fossa transpetrous approach for petroclival meningiomas. Skull Base Surg 3:130-135, 1993

11. Kassam AB, Gardner P, Snyderman C, Mintz A, Carrau R: Expanded endonasal approach: fully endoscopic, completely transnasal approach to the middle third of the clivus, petrous bone, middle cranial fossa, and infratemporal fossa. Neurosurg Focus 19(1):E6, 2005

12. Kassam AB, Prevedello DM, Carrau RL, Snyderman CH, Thomas A, Gardner P, et al: Endoscopic endonasal skull base surgery: analysis of complications in the authors' initial 800 patients. J Neurosurg 114:1544-1568, 2011

13. Labib MA, Prevedello DM, Carrau R, Kerr EE, Naudy C, Abou Al-Shaar H, et al: A road map to the internal carotid artery in expanded endoscopic endonasal approaches to the ventral cranial base. Neurosurgery 10 (Suppl 3):448-471, 2014

14. Liu J, Pinheiro-Neto CD, Fernandez-Miranda JC, Snyderman $\mathrm{CH}$, Gardner PA, Hirsch BE, et al: Eustachian tube and internal carotid artery in skull base surgery: an anatomical study. Laryngoscope 124:2655-2664, 2014

15. Megerian CA, Chiocca EA, McKenna MJ, Harsh GF IV, Ojemann RG: The subtemporal-transpetrous approach for excision of petroclival tumors. Am J Otol 17:773-779, 1996

16. Mesquita Filho PM, Ditzel Filho LF, Prevedello DM, Martinez CA, Fiore ME, Dolci RL, et al: Endoscopic endonasal surgical management of chondrosarcomas with cerebellopontine angle extension. Neurosurg Focus 37(4):E13, 2014

17. Miller CG, van Loveren HR, Keller JT, Pensak M, el-Kalliny M, Tew JM Jr: Transpetrosal approach: surgical anatomy and technique. Neurosurgery 33:461-469, 1993

18. Morera VA, Fernandez-Miranda JC, Prevedello DM, Madhok R, Barges-Coll J, Gardner P et al: "Far-medial" expanded endonasal approach to the inferior third of the clivus: the transcondylar and transjugular tubercle approaches. Neurosurgery 66 (6 Suppl Operative):211-220, 2010

19. Osawa S, Rhoton AL Jr, Tanriover N, Shimizu S, Fujii K: 
Microsurgical anatomy and surgical exposure of the petrous segment of the internal carotid artery. Neurosurgery 63 (4 Suppl 2):210-239, 2008

20. Ozturk K, Snyderman CH, Gardner PA, Fernandez-Miranda JC: The anatomical relationship between the eustachian tube and petrous internal carotid artery. Laryngoscope 122:2658-2662, 2012

21. Samii M, Metwali H, Samii A, Gerganov V: Retrosigmoid intradural inframeatal approach: indications and technique. Neurosurgery 73 (1 Suppl Operative):ons53-ons60, 2013

22. Sekhar LN, Schramm VL Jr, Jones NF: Subtemporal-preauricular infratemporal fossa approach to large lateral and posterior cranial base neoplasms. J Neurosurg 67:488-499, 1987

23. Simal-Julián JA, Miranda-Lloret P, Beltrán-Giner A, PlazaRamirez E, Botella-Asunción C: Full endoscopic endonasal extreme far-medial approach: Eustachian tube transposition. J Neurosurg Pediatr 11:584-590, 2013

24. Spetzler RF, Daspit CP, Pappas CT: The combined supra- and infratentorial approach for lesions of the petrous and clival regions: experience with 46 cases. J Neurosurg 76:588-599, 1992

25. Suhardja AS, Cusimano MD, Agur AM: Surgical exposure and resection of the vertical portion of the petrous internal carotid artery: anatomic study. Neurosurgery 49:665-670, 2001

26. Taniguchi M, Kohmura E: Endoscopic transnasal transmaxillary transpterygoid approach to the parapharyngeal space: an anatomic study. Minim Invasive Neurosurg 53:255-260, 2010

27. Tauber M, van Loveren HR, Jallo G, Romano A, Keller JT: The enigmatic foramen lacerum. Neurosurgery 44:386-393, 1999

28. Van Gompel JJ, Alikhani P, Tabor MH, van Loveren HR, Agazzi S, Froelich S, et al: Anterior inferior petrosectomy: defining the role of endonasal endoscopic techniques for petrous apex approaches. J Neurosurg 120:1321-1325, 2014

29. Zanation AM, Snyderman CH, Carrau RL, Gardner PA, Prevedello DM, Kassam AB: Endoscopic endonasal surgery for petrous apex lesions. Laryngoscope 119:19-25, 2009

30. Zimmer LA, Hirsch BE, Kassam A, Horowitz M, Snyderman $\mathrm{CH}$ : Resection of a recurrent paraganglioma via an endoscopic transnasal approach to the jugular fossa. Otol Neurotol $27: 398-402,2006$

\section{Disclosure}

The authors report no conflict of interest concerning the materials or methods used in this study or the findings specified in this paper. No financial support was received in conjunction with the generation of this manuscript.

\section{Author Contributions}

Conception and design: Taniguchi. Acquisition of data: Taniguchi, Akutsu, Mizukawa, Kohta, Kimura. Analysis and interpretation of data: Taniguchi, Akutsu, Kohmura. Drafting the article: Taniguchi. Critically revising the article: Akutsu, Mizukawa, Kohta, Kimura, Kohmura. Reviewed submitted version of manuscript: all authors. Approved the final version of the manuscript on behalf of all authors: Taniguchi.

\section{Supplemental Information Videos}

Video 1, Media Player. http://mfile.akamai.com/21490/wmv/ digitalwbc.download.akamai.com/21492/wm.digitalsource-naregional/jns14-2526_video_1.asx.

Video 1, Quicktime. http://mfile.akamai.com/21488/mov/ digitalwbc.download.akamai.com/21492/qt.digitalsource-global/ jns14-2526_video_1.mov.

Video 2, Media Player. http://mfile.akamai.com/21490/wmv/ digitalwbc.download .akamai.com/21492/wm.digitalsource-naregional/jns14-2526_video_2.asx.

Video 2, Quicktime. http://mfile.akamai.com/21488/mov/ digitalwbc.download.akamai.com/21492/qt.digitalsource-global/ jns14-2526_video_2.mov.

\section{Previous Presentation}

Portions of this work were presented in abstract form at the 11th European Skull Base Society Congress, Paris, France, June 27, 2014.

\section{Correspondence}

Masaaki Taniguchi, Department of Neurosurgery, Kobe University Graduate School of Medicine, 7-5-1 Kusunoki-cho, Chuo-ku, Kobe, Hyogo 650-0017, Japan. email: mtani@med.kobe-u.ac.jp. 